\title{
QUEEN'S
UNIVERSITY
BELFAST
}

\section{New challenges in family support: the use of digital technology in supporting parents}

Lamberton, L., Devaney, J., \& Bunting, L. (2016). New challenges in family support: the use of digital technology in supporting parents. Child Abuse Review, 25(5), 359-372. https://doi.org/10.1002/car.2451

\author{
Published in: \\ Child Abuse Review
}

\section{Document Version:}

Peer reviewed version

Queen's University Belfast - Research Portal:

Link to publication record in Queen's University Belfast Research Portal

\section{Publisher rights}

Copyright (C) 2017 John Wiley \& Sons, Ltd

This is the peer reviewed version of the following article: Lamberton, L., Devaney, J., and Bunting, L. (2016) New Challenges in Family Support: The Use of Digital Technology in Supporting Parents. Child Abuse Rev., 25: 359-, which has been published in final form at http://onlinelibrary.wiley.com/wol1/doi/10.1002/car.2451/abstract. This article may be used for non-commercial purposes in accordance with Wiley Terms and Conditions for Self-Archiving.

\section{General rights}

Copyright for the publications made accessible via the Queen's University Belfast Research Portal is retained by the author(s) and / or other copyright owners and it is a condition of accessing these publications that users recognise and abide by the legal requirements associated with these rights.

Take down policy

The Research Portal is Queen's institutional repository that provides access to Queen's research output. Every effort has been made to ensure that content in the Research Portal does not infringe any person's rights, or applicable UK laws. If you discover content in the Research Portal that you believe breaches copyright or violates any law, please contact openaccess@qub.ac.uk. 


\section{New challenges in family support: the use of digital technology in supporting parents}

\section{Abstract}

This study explores how digital technology is being used to provide innovative family support services, and the challenges and opportunities this holds for practitioners in delivering the service. Online services hold the possibility of accessing increasing numbers of parents, and providing support that fits with their own needs and availability. Using the parenting website Netmums as a case study, this article explores how staff who engage with parents online understand their role in both supporting parents and safeguarding children. This exploratory study involved in-depth semi-structured online interviews with Netmums' staff $(n=13)$. A thematic analysis identified a number of key themes, the most frequently occurring being in relation to: identifying and responding to child safeguarding concerns; and the false impression by parents of anonymity in the online environment. This exploratory research raises more questions that it can answer, especially in relation to managing child safeguarding concerns while maintaining a 'mum friendly' approach. Online interventions show promise but there is a need for further evaluation of these forms of intervention.

\section{Key Practitioner Messages:}

- Online family support services (FSS) provide an alternative, cost-effective service that can be accessed from anywhere,_increasing opportunities for parents to become agents in their own support.

- Online FSS meet a much broader and largely unfiltered range of needs compared to offline services but they raise unique challenges in identifying and managing child 
safeguarding concerns.

- In-depth research into innovative online FSS adds to the wider discussion on the future development of family support.

\section{Keywords}

Safeguarding children

Child Protection

Parents/Mothers/Fathers

Qualitative study

\section{Introduction}

The internet is now widely recognised as a source of self-help and support particularly regarding health-related matters (Pehora et al., 2015). Alongside the growth in e-health, there has been a surge in websites focusing on information and support for parenting. Dworkin et al. (2013) argue that parents are more connected to, and enthusiastic about, technology than non-parents. The implications for policy and practice are seen in the increase in online services for parents and in the social media interactions of social care organisations (Hall et al., 2009). The importance of parenting websites is becoming more widely recognised, and with the development of smartphone and tablet technology, more parents are able to access the internet throughout the day (Pedersen and Smithson, 2013).

Family support services (FSS) have increased in number in the UK due to both a legislative and a policy mandate (Department for Children, Schools and Families, 2010). Recent high profile inquiries have called for the strengthening and development of services across all 
levels of intervention (Munro, 2011). Central government has funded a number of organisations to increase the provision of online support throughout the UK (Hall et al., 2009).

This research is an exploratory study that sought to identify some of the challenges that arise in providing an online FSS._The research uses Netmums as a case study - a service that is situated at the interface between digital technology and family support. The paper begins with a brief overview of the policy, conceptual and theoretical context of online FSS, from which the case of Netmums can be better understood.

Background

All parents are encouraged to access universally provided FSS to help address their needs and those of their children (Lewis, 2011). However, and as Rake et al. (2011) highlight, parenting has become one of the most charged political and cultural subjects of our age. The subsequent scrutiny of parenting has led to the idea of a parenting 'deficit' and a view that there are an increasing number of parents who are 'incapable'. This situation has the potential to deskill parents, raising their anxiety and guilt. There is now an elusive 'holy grail' of perfect parenting, in which parents are 'expected to acquire detailed knowledge of what the experts consider proper child development and then spend a good deal of time and money attempting to foster it' (Hays, 1996, p.8).

Parents Online

The pressure felt by parents for 'expert' input, alongside the reduction in contact with extended families and a greater sense of social isolation, is leading an increasing number of parents to access support and information online (Plantin and Daneback 2009). Online media provide a range of different supports. These include: information, often endorsed by 
health and behaviour experts; and online services, such as live chat, giving support and information on specialist topics, and delivered by organisations such as Family Rights Group, Contact a Family and Coram Children's Legal Centre, or by online communities.

Preece (2000) describes an online community as an internet-connected collective of people who interact over time around a shared purpose, interest or need, and which is reliant on people's voluntary commitment, participation and contributions. Rothbaum et al. (2008) highlight how these virtual communities are becoming an increasingly important source of advice and support, not only for isolated parents but also for those with sufficient local support around them (Pedersen and Smithson, 2013). Parents have described parenting websites and forums as generally safe and supportive places, where they can better understand the role they play as a parent to their children (Madge and O'Connor, 2006). Digital technology provides an easy, accessible way for parents to access the information they need when it suits them (Plantin and Daneback, 2009).

The present research considers one of these online communities, Netmums Parent Supporter Project (PSP), which has been further professionalised by the addition of a layer of expert support alongside the existing peer to peer support from the online community.

Online Family Support

It is important to briefly consider where online family support sits within the wider family support framework. The term 'family support' is so widely used that 'it has almost lost its meaning or rather it encompasses so many meanings that it is difficult to disentangle them' (Penn and Gough, 2002, p.17). The Department of Health, Social Services and Public Safety, in Northern Ireland, has defined family support as:

'The provision of a range of supports and services to ensure that all children and 
young people are given the opportunity to develop to their full potential. It aims to promote their development primarily by supporting and empowering families, and strengthening communities. Its focus is on early intervention, ensuring that appropriate assistance is available to families at the earliest opportunity at all levels of need.' (DHSSPS, 2009, p.18)

This definition was used within this study.

Drawing upon an ecological perspective, Hardiker et al. (1991) developed a model to help understand the different levels of need within a population of children. Level 1 refers to the mainstream universal services available to all children, such as education and health care; Level 2 refers to services for children with some additional needs, such as parenting or behaviour support; Level 3 represents support to families where there are chronic or serious problems, such as child protection concerns, often with a number of agencies working together; and Level 4 involves support where the family has 'broken down' temporarily or permanently, and the children need to be looked after by social services or inpatient care. For the purposes of this research, Netmums PSP is viewed as a universal support as per the Hardiker et al. (1991) model, available to all parents who have internet access.

While there are some crossovers with more traditional family support, the motivations to seek support online differ from those pertaining to accessing support offline. Pedersen and Smithson (2013) argue that a successful online community must be able to offer different satisfactions to different users simultaneously. The main motivational factors for users are the need for support and advice in terms of learning from the experience of others; having their own experiences and expertise validated; supplementing information given to them by health and other professionals; acting out their role as caregivers, even when away from their children; and getting advice and support from anonymous others from varying backgrounds and with differing experiences (Pedersen and Smithson, 2013; Rothbaum et 
al., 2008; Wang et al., 2002). Anonymity can be an especially attractive feature, particularly when a parent is addressing their own mental health needs or the challenges associated with the special needs of children (Fleischmann, 2004). Advice can be easier to take from strangers than family and friends (Morrow, 2006).

Online FSS can meet a much broader and largely unfiltered range of needs, compared to offline services, which usually have referral criteria. Power, within the online arena, is shifted from the service provider to the service user, leaving potential challenges in managing issues around child safeguarding, a concept that has not been explored fully in the literature. As with offline FSS, there is a need to be mindful that some children need additional support and protection from the State, and as such this study sought to explore with staff how these issues present themselves and the responses with which they are met.

Netmums Parent Support Project

Netmums.com was founded in 2000 and is the fastest growing online parenting organisation in the UK, i.e. 'Netmums.com ... is the fastest growing online parenting organisation in the UK', with more than 1.7 million members and 8 million unique users each month (Netmums, 2016). Founded by three mothers, it aims to 'help mums enjoy a happy and healthy family life' (Netmums, 2016). The key philosophies of the organisation are focused on: supporting parents who are experiencing difficulties (by providing reliable advice to them when they are struggling with particular conditions or situations, such as post-natal depression); and encouraging parents not to place unrealistic expectations on themselves. Alongside the editorial information on all aspects of parenting, and extensive paid for advertising of products, Netmums developed a Parent Support Project (PSP). The PSP was formed in 2008 , with the aim of 'adding a layer of expert help to our community of parents who support each other' (Netmums, 2016). Through the PSP, trained practitioners from health and social care backgrounds, including health visitors, social workers and midwifes, were employed to 
deliver advice and support, i.e. 'Through the PSP, trained practitioners from health and social care backgrounds... were employed to deliver advice and support']. In 2011, the PSP received four years funding from the Department for Education, in England, to further develop this innovative online support service. The support was delivered seven days a week through collaboration with a number of voluntary organisations, including the Family Rights Group, Relate, Women's Aid England, Contact a Family and Citizens Advice Bureau. This funding ended in March 2015, and the PSP was scaled back and is now funded entirely by Netmums. This research was conducted in the last year of the funding, amidst uncertainties regarding the future of the project.

Support, within the PSP, is provided through members posting on a number of forums within the Coffeehouse, which is a discussion forum allowing for the development of online virtual communities focused on specific topics. Alongside subjects such as Babies, Children, Food and Feeding, there is an Advice and Support section. This latter section covers a range of issues, including Antenatal and Postnatal Depression, Are you being Badly Treated? (Domestic Violence Support), and The Serious Stuff. In order to post, a service user must be registered on the site, giving their (real) name, postcode and email address. Their IP address (a unique code for a computing device that identifies one device to another) is collected automatically. At this stage, users are made aware of the terms and conditions of the site, including the limits on confidentiality and anonymity, whereby information may be passed on to relevant agencies if there are child safeguarding concerns. There is an option to post semi-anonymously, whereby the community cannot see any posting history or usernames even though staff can. Having posted on these discussion boards, members can receive both peer and practitioner replies. The practitioners work only on the Advice and Support section. There is a report function on the website, and if members see a post that concerns them, they can highlight this to a moderator who passes the information on to the PSP team.

While the service is not exclusive to women, the website is mostly used by mothers. 
However, other care givers, including grandparents, foster parents and fathers, do post for support, and therefore the term 'parent' will be used in this paper. The practitioners focus on supporting members by providing evidence-informed advice to them, or by facilitating their getting help from other organisations, either through a referral to a partner agency (which replies on the thread'), or by signposting them to local (offline) agencies.

Frequently, posts develop into a discussion between the member and the practitioner. The practitioner undertakes more in depth work with the member, examining the identified issues and providing her or him with ongoing emotional support. Child safeguarding concerns emerge regularly, and are closely monitored by staff, with serious concerns being referred to local agencies, such as children's services as per the safeguarding policy.

PSP staff members all work remotely from their homes, which are located throughout the UK, with a central office in London, which runs other aspects of the website. Staff work set shifts in teams, and communicate with each other via Skype Instant Messaging (IM) service. Individual staff are responsible for a specific forum in three hour blocks, with the team leader and the head of support available as required. All staff receive regular clinical supervision, and take part in face to face staff meetings and training twice a year.

Aims of the study

The aim of this research was to explore how digital technology is being used to provide innovative FSS in the UK (covering England, Wales, Scotland and Northern Ireland) through considering one service: the Netmums PSP. The research aimed to focus on the practitioner perspective, exploring the nature of this type of online support service, which had grown organically from the development of a virtual community. More specifically, it sought to focus on the dilemmas and tensions experienced by staff contributing to the forums to support parents and address child safeguarding concerns. Moreover, the study explored how these 
concerns were managed and the potential implications of these responses for the wider development of online support services. Alongside developing further insight into the nature and remit of the PSP, the key research questionwas: How is child safeguarding ensured when supporting parents online and what are the practitioners' experiences of this process?

\section{Methods}

Sample

As this was an exploratory study, an inductive qualitative methodology was selected, involving online semi-structured interviews conducted by the lead author, who was also an employee of Netmums. Permission was granted by Netmums to conduct the research and subsequently all staff $(n=20)$ were invited to take part and were provided with a participant information sheet and consent form. Participants were able to withdraw at any time. Of the 20 participants approached, seven declined to take part for a variety of reasons. These reasons included not having enough time, feelings of anxiety (due to pending redundancies), being away from work (owing to maternity leave) and a belief that they had not worked long enough on the PSP to be able to contribute meaningfully to the research. The participants $(n=13)$ were all professionally trained paid staff and had been employed for at least one year.

Research instrument

A topic guide was developed for the interviews; one that was based on a comprehensive review of the literature. It focused on: gaining an understanding of the background of the participants; their employment history with Netmums; their understanding of the PSP; what 'positives' and challenges they had experienced during their work with the service; and a discussion of Netmums' policies and procedures. During the interview process, child safeguarding was raised by each participant, and was explored in more detail. This included 
asking participants about: specific instances where they had felt concerned about child safeguarding; the subsequent reporting and referral processes; and whether they were satisfied with the outcome of these processes.

Research procedure

Real time synchronous interviews were carried out via an IM service._This reflected the way that staff communicate with each other to deliver the service. Interviews took 1.5 to 2 hours. Online interviews have increasingly been used as a form of data collection. These tend to be asynchronous email interviews (Illingworth, 2001). There are few documented reports of synchronous online interviews; with this method tending to be viewed as relatively novel and innovative (O'Connor et al., 2008). Until relatively recently, technology made these real time interviews practically difficult. However, with the development of IM services, they are becoming more feasible. Netmums utilises the IM service for most of the interaction between staff members. Therefore, this familiar service was the most appropriate method to conduct synchronous interviews.

Second stage interviews were conducted with individual staff members to further consider some of the issues that arose in the initial interviews. In order to quality assure the analysis process, each interviewee received a summation of the analysis of her interview to enable her to check that it was accurate. This provided some triangulation to validate the research.

Ethical approval was granted by Queen's University Belfast School of Sociology, Social Policy and Social Work Research Ethics Committee.

Analysis

Thematic analysis was elected as the analytical approach_given that the primary goal of the 
research was to describe and understand how people feel, think and behave within a specific context and in line with a particular research question (Guest et al., 2012). A five stage framework was developed drawing upon the model described by Guest et al., (2012) and adapted to be used within NVivo. Stage 1 involved the development of a code manual following a familiarisation process with the data and topic guide; stage 2 summarised the data, identifying the initial themes, within NVivo, as nodes; in stage 3, a template of codes was applied through analysing linguistic connections, thereby allowing additional coding to take place; stage 4 was an inductive process focusing on connecting the codes and identifying emerging themes; and stage 5 refined and further clustered the themes corroborating and legitimating them.

Being a participatory study, the notion of reflexivity was an imperative._At a basic level, reflexivity allows the researcher to develop greater awareness of his or her role within the research process (Denzin and Lincoln, 2011). Developing greater awareness was especially important in this study, given the three distinct roles held by the lead author vis a vis Netmums: as a colleague to staff members, with her own experiences and opinions on the Netmums' service, which undoubtedly shaped her perspectives; as a researcher; and as a mother who uses these sort of parenting services, both as a staff member and for her own personal use. These three roles gave the lead author a unique perspective as a user but also as a creator of online parenting discussions. In order to avoid sharing simply her experiences of the Netmums' service, the lead author sought to work in partnership with her colleagues, presenting them with a summation of the analysis process to ensure that they were represented accurately (Guest et al., 2012).

\section{Findings}

Overview 
A number of key themes emerged concerning a range of aspects of work at Netmums. These included descriptions of the nature and delivery of the PSP, with reports of high levels of motivation and job satisfaction from staff. A number of participants highlighted their concerns regarding the lack of job security (which was due to issues over funding) and the negative impact of this on the workforce. The challenges in maintaining an appropriate worklife balance when working from home were highlighted by all staff. The most frequently occurring theme discussed was in relation to the unique and specific challenges of identifying and responding to child safeguarding concerns in the online community, and how procedures surrounding this issue had developed.

Specialised skills

Operating in this online environment raised a number of subthemes around unique ways of working. While staff felt that many offline skills were transferable, they all reported that they had, over time, developed ways of working that were unique to the online environment. In particular, participants felt that they had formulated specialised skills to demonstrate empathy and support via words on a screen._One staff member described this in comparison to her other role as a healthcare professional in the community:

'Not knowing the context of a post, you know nothing about them, age, cultural background etcetera, only what they tell you. You have to feel your way very carefully, and ask lots of open questions but often it is what isn't said that is important.'

Misuse of service

Challenges in addressing difficult online behaviours, such as the intentional misuse of the 
service through trolling and other attention-seeking behaviour, as well as monitoring potential cyberbullying, were frequently raised by participants. As all the forums are open to peer support, some responses can be less than supportive. Occasionally, inflammatory remarks are made, leading to disputes that can escalate very rapidly. Many of these issues were dealt with by the moderators, part of whose role was to address the inappropriate use of the forums.

These situations did, however, raise challenges for staff in respect of their being able to respond in measured ways that would still add value for a member or for those who simply read the advice and did not wish to become involved in the written discussions. Members can post across different boards, fragmenting their 'story', creating further challenges for staff:

'The other night a mum said that she had been depressed in the past and didn't want social services involved after saying she had "lost" her two children. Mums who replied thought they [the children] died, yet that wasn't the case. I felt I needed to respond so that the mum understood what I meant without seeming callous, and enabling her to tell more of her story if she wanted to.'

Child safeguarding

There is a very well developed child safeguarding process within Netmums, which has taken time to develop. Using the guiding principle of 'Where is the child in this?', staff are encouraged to place the child at the centre of considerations. This interaction, though, often takes place in the midst of families experiencing complex and difficult situations, such as domestic violence, substance misuse and parental mental illness. If a child is judged to be at risk of immediate significant harm, a senior manager is contacted to facilitate onward urgent 
referral to statutory services as appropriate. The majority of concerns are more subtle in nature, as service users post concise summaries of incidents such as domestic violence and it is unclear if children are involved. It can take dialogue with the service user, over a period of time, to establish what risks are present._These types of safeguarding issues are managed through the 'cause for concern process', in which the work of staff is systematically monitored during every shift. A plan of support is developed, and, as far as is possible, staff seek to engage with members to ensure they are receiving appropriate support from the PSP and in the community. If this support is not in place, it may be necessary to refer on to local health or social care services. However, this process has taken time to develop as pointed out by the following participant:

'There is a thorough process in terms of how this is managed with the $\mathrm{C} 4 \mathrm{C}$ [Cause for Concern] framework, which has evolved since I have started, and there have sometimes been conflicts between professionals' views about whether a case requires referral, and how the management/directors have viewed issues. I do feel that this has been ironed out now and that we are all clearer about how to proceed in these circumstances - or where to ask for additional support and advice.'

Most staff believed there had been a big improvement in the child safeguarding process. However, some staff felt that there were still limitations, as indicated by the following participant: 'it's still not ideal but that might be as a consequence of the nature of online work'. Working directly with parents means that sometimes the 'parents are prioritised at times over the needs of the child'. One staff member highlighted the difficulties in the safeguarding process while expressing her positivity about the service:

'The ethos behind it and having professionals involved in this ensures 
there is a supportive moderated environment and parents get safe, evidence-based information, and children and vulnerable adults are safeguarded to an extent.'

When asked about her use of the term 'to an extent', this participant discussed the problems in recognising and identifying 'risky' situations online. She continued: '[In my previous role], you visited them at home, which spoke volumes; you could see them, and pick up on nonverbal clues'.

Confidentiality and anonymity

Many staff pointed out that members could be quite open online and make disclosures of potential child abuse or neglect, whilst not fully appreciating the potential consequences, i.e. 'Many staff pointed out that members could be quite open online and make disclosures... whilst not fully appreciating the potential consequences' of this:

'I also think that members may be more open than they would be in person and this means that they may not realise the implication about what they post online.'

All participants highlighted issues around confidentiality and whether service users are aware of the data that is collected by Netmums, and particularly the potential for that information to be used to refer on to other services when serious incidents such as domestic violence or child abuse are reported. Although this is explicitly detailed in the terms and conditions when a member signs up on the website, two participants questioned the effectiveness of this procedure: 
'Many members will post under a false or altered name. However, whilst they are unknown to the public, 'we' often do know exactly who they are. Of course we do tell people in the small print... but I certainly didn't think about it when I joined as a member years ago.'

'I think that many forget we can find out who they are even when posting anonymously. It is made clear to them when they become a member but they may forget this. They are often shocked that we can trace them.'

Triggering referrals

One participant explained that a small number of members use the child safeguarding process to trigger contact with local services, by uploading suicidal posts. These members are well known to staff and have been referred to other agencies on previous occasions:

'A handful of members are very aware indeed. And I suspect know what triggers they can use to initiate contact between Netmums and their local team. On the whole, though, I suspect very few know the implications of posting what they do on Netmums.'

\section{Discussion}

It is well documented that online support for parents meets a number of needs, including acquiring parenting information and accessing social support (Dworkin et al., 2013; Plantin and Daneback, 2009). Madge and O'Connor (2006) argue that these parents are not only provided with virtual social support but are also given opportunities to occupy positions of agency in the production of parenting-related knowledge. These outcomes, in turn, build 
social capital and give validation of 'normalcy' to experiences (Drentea and Moren-Cross, 2005). This latter concept is linked to social support theory (Dolan et al., 2006), which recognises the role of social support as a proven buffer to stress (Eckendrode and Hamilton, 2000), decreasing parental sense of isolation, and opening access to advice and companionship. Netmums is a key provider in the UK of all aspects of parenting information. What distinguishes it from other websites is the PSP, which adds a layer of professional support to the virtual community. Hall et al. (2009) in their evaluation of the Telephone Helplines and Innovation Fund strands of the Parent Know How programme, found that it was a costeffective means of reaching a large number of service users. (The PSP was funded through the Innovation Fund strand.) Web services were particularly useful in helping to overcome parents' feelings of isolation. However, there was no consideration given to whether there is any added benefit in having staff on the forums rather than just peer support, or if this arrangement alters the support given. These questions cannot be answered without more detailed research into service users' experiences. From the staff point of view, they strongly view the supplementation of community support with professional support as very important and an exciting aspect of their role, i.e 'Staff... view the supplementation of community support with professional support as very important and an exciting aspect of their role'.

There can, though, be ethical issues around users' understanding of the service, especially in respect of informed consent, confidentiality and anonymity. Despite terms and conditions explicitly highlighting the limits of confidentiality, there is an issue as to how aware members are, when they sign up to the service, that their information can be shared with other agencies. The reflections of staff when they personally signed up to the website, suggest that members do not consider this issue in any depth. At a structural level, this reflects some of the challenges in the boundary between the 'private' and the 'public' online (Bruckman, 2004). There is an illusion of privacy when using forums and a form of perceived anonymity. Meho (2006) highlights how the internet may encourage people to discuss topics or disclose more details more readily than they would in face-to-face situations. However, much of this 
sensitive content is in effect in the public arena and there is often a mismatch between an individual's expectation of privacy and reality. Barnes (2004) describes this as an illusion of privacy, in the sense that users often do not realise the vast number of 'lurkers' on a website and the potential for a large audience to read their posts. Often, those who post feel that they are engaging only with the small numbers who respond to their post. Eynon et al. (2008) describes this notion as 'privacy in public'. It can be argued that forums can be viewed as both private and public.

Bakardjieva and Feenberg (2001) take this issue further arguing that the core ethical issue in online family support work (and research around this) is not privacy but alienation, which is described as the 'appropriation of the products of somebody's actions for purposes never intended or foreseen by the actor herself, drawing these products into a system of relations over which the producer has no knowledge or control' (p.236). In order to be mindful of this, attention needs to be given to what an individual's intention is when they post on a forum. For example, what are their expectations regarding the use of this information? This issue also has implications for working and researching in the online field more generally.

The nature of some of the posts can raise further challenges for staff in assessing risks to children. A tired, fraught, emotional outburst from a drained parent, in what is perceived to be a 'safe community', may be similar to lifting the phone and 'offloading' to a close friend, i.e. 'A tired, fraught, emotional outburst [online]... may be similar to lifting the phone and 'offloading' to a close friend'. This resonates with the work of Drentea and Moren-Cross (2005) who identified three main categories of communication on internet parenting websites, one of which was emotional support, which includes 'venting' to deal with stress and frustration. (The other two categories being instrumental support, both formal and informal, from anecdotal and professional sources; and community building/protection in which members reacted against anyone who they perceived to be violating the norms of the group.) However, when views or experiences are recorded, in an online post, they may trigger 
significant concerns regarding the wellbeing of a child. Occasionally, members cannot be traced. Some avoid being traced through the use of mobile IP addresses and false details, which raises further challenges should concerning information be disclosed. If organisations are delivering online services, the implications of this need to be considered.

This blurring of the boundary between what is public and what is private online, along with the often false impression of confidentiality and anonymity, raises issues regarding the delivery of an online FSS. This is compounded by a lack of guidance on how to make judgements in terms of child safeguarding when presented with limited information in an online context

Limitations of study

This is an exploratory study with several limitations. Due to the small size of the study and the focus on only one service, any conclusions have to be tentative in nature, limiting transferability (Morse, 2000). The lead author being a colleague may have impacted upon the ability of participants to be totally honest in their reflections (Murray and Lawrence, 2000). Due to the impending redundancies, participants' views may have been coloured. Moreover, the data was collected, coded and themes identified by only one person. Utilising NVivo software and using a thematic analysis approach can lead to a degree of fragmentation of the textual materials (Weaver and Atkinson, 1994). Tabulating the themes, and using these as the focus of discussion, may have lost some of the narrative flow of the enquiry.

\section{Conclusions}

As an exploratory study, this research poses more questions than it can answer. Despite this, a number of tentative conclusions can be outlined. With the likely increase in 
developments in technology and the proliferation of information online, parents' use of the internet will undoubtedly grow. As the demand for parenting knowledge grows, so will the supply of information (Dworkin et al., 2013). Parenting is one of the most highly charged political and cultural subjects of our age (Rake et al., 2011), and this tension can influence FSS and social care as a whole.

Online parenting support offers opportunities for sharing social support and enhancing parental knowledge (Nieuwboer et al., 2013). However, there is a lack of research into the effectiveness of these resources (Niela-Vilén et al., 2014). It is important to consider more fully the potential impacts of online FSS.

In order to gain a more detailed understanding of online FSS, further research is also required to explore the ethical challenges around confidentiality, anonymity, and the boundary between what is public and private online. Research into other online FSS, through an ethnographic perspective, to incorporate service users' views, would be important. One aspect of this should be an investigation of the role of professional input into these online communities. For example, does this additional input make a difference in the way that service users use the service? How does an individual's use of online information and services impact upon her consumption of offline resources? Further to this, an understanding of social care professionals' understanding of online FSS, and how they handle any referrals they receive, could add to the body of research and have an impact on the future policy and practice development of both online and offline FSS.

\section{Acknowledgements}

The authors wish to thank the staff of Netmums who participated in the study. 


\section{References}

Bakardjieva M, Feenberg A. 2001. Involving the virtual subject. Ethics and Information Technology 2(4): 233-240. DOI: 0.1023/A:1011454606534

Barnes SB. 2004. Issues of attribution and identification in online social research. In: Online Social Research: Methods, Issues, and Ethics, Johns MD, Chen SS \& Hall GJ (eds). Peter Lang: New York; pp. 203-222.

Bruckman A. 2002. Studying the amateur artist: a perspective on disguising data collected in human subjects research on the Internet. Ethics and Information Technology 4(3): 217-231. DOI: 10.1023/A:1021316409277

Department for Children, Schools and Families. 2010. Parenting and Family Support: Guidance for local authorities in England. DCFS: London.

Department of Health, Social Services and Public Safety. 2009. Families Matter: Supporting Families in Northern Ireland Regional Family and Parenting Strategy. DHSSPS: Belfast.

Denzin N, Lincoln YS. 2011. The Sage Handbook of Qualitative Research. Sage: London.

Dolan P, Canavan J, Pinkerton J. 2006. Family Support as Reflective Practice. Jessica Kingsley Publishers: London.

Drentea P, Moren-Cross J. 2005. Social capital and social support on the Web - the case of an Internet mother site. Sociology of Health and IIIness 27(7): 920-943. DOI: 
Dworkin J, Connell J, Doty J. 2013. A literature review of parents' online behavior.

Cyberpsychology: Journal of Psychosocial Research on Cyberspace 7(2): 1. DOI: 10.5817/CP2013-2-2

Eckenrode J, Hamilton SK. 2000. One-to-One Support Interventions. In: Social Support Measurement and Intervention - A Guide for Health and Social Scientists, Cohen S, Underwood LG \& Gottlieb G (eds). Oxford University Press: Oxford.

Eynon R, Fry J, Schroeder R. 2008. The Ethics of Internet Research. In: The SAGE Handbook of Online Research Methods, Fielding N, Lee RM \& Blank G (eds). Sage: London.

Fleischmann A. 2004. Narratives published on the internet by parents of children with autism. Focus on Autism and other Developmental Disabilities 19(1): 35-43. DOI: $10.1177 / 10883576040190010501$

Guest G, MacQueen K, Namey E. 2012. Applied Thematic Analysis. Sage: London.

Hardiker P, Exton K, Barker M. 1991. Policies and Practices in Preventive Child Care. Ashgate: Aldershot.

Hall N, Day L, Scott L. 2009. Parent Know How: Telephone Helplines and Innovation Fund Strands Evaluation. Research Report DCSF- RR167. Department for Children, Schools and Families: London.

Hays S. 1996. The Cultural Contradictions of Motherhood. Yale University Press: New Haven, CT. 
Illingworth N. 2001. The Internet Matters: Exploring the Use of the Internet as a Research Tool. Sociological Research Online 6(2). Available:

http://www.socresonline.org.uk/6/2/illingworth.html [18 July 2016].

Lewis J. 2011. Parenting programmes in England: policy development and implementation issues 2005-2010. Journal of Social Welfare and Family Law 33(2): 107-121. DOI: $10.1080 / 09649069.2011 .617068$

Madge C, O'Connor H. 2006. Parenting gone wired - empowerment of new mothers on the Internet. Social and Cultural Geography 7(2): 199-220. DOI:

$10.1080 / 14649360600600528$

Meho L. 2006. E-mail interviewing in qualitative research: a methodological discussion. Journal of the American Society for Information Science and Technology 57 (10): 1284-95. DOI :10.1002/asi.20416

Morrow PR. 2006. Telling about problems and giving advice in an internet discussion forum: Some discourse features. Discourse Studies 8: 531-548. DOI: $10.1177 / 1461445606061876$

Morse JM. 2000. Determining sample size. Qualitative Health Research 10(1): 3-5. DOI: $10.1177 / 104973200129118183$

Munro E. 2011. The Munro Review of Child Protection: Final Report. A Child-Centred System. Department for Education: London.

Murray L, Lawrence B. 2000. The basis of critique of practitioner-based enquiry. In: 
Practitioner-based Enquiry: Principles for Postgraduate Research, Murray L \& Lawrence B (eds). Falmer Press: London; pp. 16-34.

Netmums. 2016. About Us. Available: http://www.netmums.com/home/about-us [19 July 2016]

Nieuwboer CC, Fukkink RG, Hermanns JMA. 2013. Online programs as tools to improve parenting: A meta-analytic review. Children and Youth Services Review 35: 18231829. DOI: 10.1016/j.childyouth.2013.08.008

Niela-Vilén H, Axelin A, Salanterä S, Melender HL. 2014. Internet-based peer support for parents: A systematic integrative review. International Journal of Nursing Studies 51: 1524-1537. DOI: 10.1016/j.jnurstu2014.06.009

O'Connor H, Madge C, Shaw R, Wellens J. 2008. Internet-based Interviewing. In The SAGE Handbook of Online Research Methods, Fielding N, Lee RM \& Blank G (eds). Sage: London.

Pedersen S, Smithson J. 2013. Mothers with attitude - How the Mumsnet parenting forum offers space for new forms of femininity to emerge online. Women's Studies International Forum 38: 97-106. DOI: 10.1016/ j.wsif2013.03.004

Pehora C, Gajaria N, Stoute M, Fracassa S, Serebale-O'Sullivan R, Matava CT. 2015. Are Parents Getting it Right? A Survey of Parents' Internet Use for Children's Health Care Information. Interactive Journal of Medical Research 4(2): e12. DOI: 10.2196/ijmr.3790

Penn H, Gough D. 2002. The price of a loaf of bread: some conceptions of family support. Children and Society 16: 17-32. DOI: 10.1002/chi.684 
Plantin L, Daneback K. 2009. Parenthood, information and support on the internet. A literature review of research on parents and professionals online. BMC Family Practice 10: 34. DOI: 10.1186/1471-2296-10-34

Preece J. 2000. Online communities: Designing usability, supporting sociability. Wiley: Chichester.

Rake K, Grigg P, Hannon C. 2011. Parenting Under the Microscope. In: Where now for parenting? Perspectives on parenting, policy and practice, FPI (eds). Family and Parenting Institute: London.

Rothbaum F, Martland N, Janssen JB. 2008. Parents' reliance on the web to find information about children and families — socio-economic differences in use, skills and satisfaction. Journal of Applied Developmental Psychology 29(2): 118-128. DOI: 10.1016/j.appdev.2007.12.002

Wang Y, Quaehee Y, Fesenmaier DR. 2002. Defining the virtual tourist community: implications for tourism marketing. Tourism Management 23(4): 407-417. DOI: $10.1016 / \mathrm{s} 0261-5177(01) 00093-0$

Weaver A, Atkinson P. 1994. Microcomputing and Qualitative Data Analysis. Avebury : Aldershot, Hants. 